\title{
Sonographic Measurement of Fetal Pinna Length in Normal Pregnancies
}

\author{
Joshi KS, ${ }^{1}$ Chawla CD, ${ }^{2}$ Karki $S,{ }^{1}$ Shrestha $\mathrm{NC}^{3}$
}

\author{
${ }^{1}$ Department of Radiodiagnosis and Imaging \\ ${ }^{2}$ Department of Obstetrics and Gynecology \\ ${ }^{3}$ Department of Pediatrics \\ Dhulikhel Hospital - Kathmandu University Hospital \\ Kavrepalanchowk, Nepal.
}

\section{Corresponding author:}

Kirti Subas Joshi

Department of Radiodiagnosis and Imaging

Dhulikhel Hospital - Kathmandu University Hospital

Kavrepalanchowk, Nepal.

email: joshisubas@hotmail.com

\section{Citation}

Joshi KS, Chawla CD, Karki S, Shrestha NC. Sonographic measurement of fetal pinna length in normal pregnancy. Kathmandu Univ Med J 2011;34(2)49-53.

\begin{abstract}
Background

Many studies have emphasized on fetal pinna measurements and morphologic features to use this structure as an additional marker for fetal chromosomal anomaly.

\section{Objectives}

To assess relationship between fetal pinna length and gestation age and develop a nomogram. To assess relationship between fetal pinna length and head circumference and biparietal diameter.
\end{abstract}

\section{Methods}

Fetal pinna measurements from the tip of helix to the end of lobe were obtained prospectively in 850 singleton pregnant women between 15 and 40 weeks' gestation Normal case was defined as normal sonographic findings during examination and normal infant examination at birth or both. Final study population was 787 . The relationship between gestational age in weeks to pinna length in millimeters was analyzed by simple linear regression. Correlation of fetal ear length measurements with gestational age, biparietal diameter and head circumference were also obtained.

Results

Linear relationships were found between fetal pinna length and gestational age [Pinna Length $(\mathrm{mm})=1.044 \times$ Gestational age (weeks) -3.857 ]. A nomogram of normal pinna length was obtained. High correlation was found between pinna length and gestational age $(r=0.942 ; p<0.001)$, pinna length and head circumference $(r=0.931$; $p<0.001)$. Significant correlation was found between pinna length and biparietal diameter $(r=0.934 ; p=0.004)$

\section{Conclusions}

The results of this study provide a nomogram for fetal pinna. The study also provides relationship and good correlation between pinna length and other biometric measurements.

\section{KEY WORDS}

gestational age, pinna length, sonography

\section{INTRODUCTION}

Abnormal fetal pinna lengths are features of many chromosomal anomalies and aneuploid conditions. ${ }^{1,2,3}$ Many studies have emphasized on fetal pinna measurements and morphologic features in an attempt to use this structure as an additional marker for fetal chromosomal anomaly. ${ }^{4-8}$ But routinely we do not give much attention to this small but important structure during our routine antenatal scan. Fetal pinna length is however a simple measurement which can be obtained in nearly all fetal ultrasonographic examinations from early second trimester till term. Moreover ultrasound is one of the most popular, cheap, non-hazardous and easily available imaging modality in our country. Hence many of the practicing radiologists/ sonologists can make a routine to assess this important structure. This helps to suspect chromosomal anomalies and aneuploid conditions early in gestation.

There are handful numbers of studies in the English literature journals that give prenatal standard for fetal pinna 
length. ${ }^{6,9,10}$ One of the studies even used 3-D ultrasound to evaluate fetal pinna. ${ }^{11}$ But they are focused mostly on Western population. We have taken a step to define a nomogram for fetal pinna length in normal second and third trimester pregnancies in our country. This helps to define normal and abnormal fetal pinnas in our population which we belief is different from Western data as other anthropometric measurements.

\section{METHODS}

This is a hospital based cross sectional study. For type I and type II errors of $5 \%$ and $20 \%$ respectively, total number of subjects (N) was calculated by the formula 32/ES2, where $\mathrm{ES}$ is the smallest effect size worth detecting. Because a correlation of 0.1 is equivalent to the effective size of 0.2 , total minimal sample required was 800 . After institutiona research committee approval, fetal pinna measurements were obtained prospectively in 850 singleton pregnant women between 15 and 40 weeks' gestation in Dhulikhel Hospital, Kathmandu University Hospital over a 15 month period between May 2010 and July 2011.

The inclusion criteria were normal sonographic findings during examination and normal infant examination at birth or both. The cases with sonographic abnormalities Table 1. Normogram of fetal pinna length (in millimeters) according to percentile distribution.

\begin{tabular}{|c|c|c|c|c|c|c|c|c|}
\hline $\begin{array}{l}\text { Gestation } \\
\text { (weeks) }\end{array}$ & No. of fetuses & 5 & 10 & 25 & 50 & 75 & 90 & 95 \\
\hline 15 & 10 & 8.18 & 8.36 & 9.00 & 9.20 & 10.08 & 11.47 & 12.24 \\
\hline 16 & 12 & 8.83 & 9.54 & 9.98 & 10.60 & 13.03 & 13.97 & 14.00 \\
\hline 17 & 12 & 12.91 & 13.02 & 13.43 & 14.20 & 14.73 & 15.25 & 15.35 \\
\hline 18 & 11 & 12.55 & 12.70 & 13.80 & 15.00 & 16.20 & 16.70 & 17.05 \\
\hline 19 & 23 & 14.00 & 14.00 & 15.55 & 16.00 & 17.25 & 17.94 & 18.00 \\
\hline 20 & 60 & 15.00 & 15.40 & 16.00 & 17.00 & 18.00 & 19.60 & 20.00 \\
\hline 21 & 88 & 15.80 & 16.00 & 17.00 & 17.90 & 19.00 & 20.20 & 20.90 \\
\hline 22 & 92 & 16.20 & 17.00 & 18.00 & 19.00 & 20.00 & 21.40 & 22.50 \\
\hline 23 & 63 & 17.00 & 17.60 & 18.40 & 20.00 & 21.40 & 22.60 & 22.80 \\
\hline 24 & 52 & 18.50 & 19.10 & 19.90 & 20.90 & 22.40 & 23.60 & 24.00 \\
\hline 25 & 35 & 18.90 & 19.10 & 20.00 & 21.90 & 23.00 & 24.20 & 24.60 \\
\hline 26 & 39 & 21.00 & 21.20 & 22.40 & 23.70 & 25.50 & 26.80 & 29.00 \\
\hline 27 & 21 & 21.60 & 22.20 & 23.00 & 25.00 & 27.30 & 28.60 & 28.60 \\
\hline 28 & 20 & 24.40 & 24.90 & 25.50 & 26.40 & 27.10 & 28.10 & 28.50 \\
\hline 29 & 18 & 23.90 & 24.40 & 25.00 & 28.10 & 29.90 & 31.60 & 33.60 \\
\hline 30 & 21 & 25.00 & 25.00 & 27.00 & 28.00 & 29.20 & 31.10 & 31.30 \\
\hline 31 & 17 & 26.20 & 26.30 & 27.00 & 28.30 & 29.90 & 30.20 & 31.00 \\
\hline 32 & 29 & 26.40 & 27.30 & 28.00 & 30.00 & 31.20 & 32.20 & 33.60 \\
\hline 33 & 24 & 24.70 & 25.70 & 28.00 & 31.40 & 34.00 & 34.60 & 35.00 \\
\hline 34 & 30 & 27.10 & 27.70 & 29.60 & 32.20 & 34.30 & 36.10 & 37.40 \\
\hline 35 & 33 & 29.30 & 30.20 & 31.10 & 32.60 & 34.00 & 35.80 & 38.10 \\
\hline 36 & 24 & 30.00 & 30.50 & 31.90 & 34.00 & 35.60 & 36.80 & 37.40 \\
\hline 37 & 18 & 29.90 & 30.40 & 33.70 & 35.10 & 36.40 & 37.90 & 38.20 \\
\hline 38 & 13 & 30.90 & 31.30 & 32.20 & 34.00 & 37.70 & 38.20 & 38.50 \\
\hline 39 & 12 & 29.60 & 29.90 & 32.10 & 34.90 & 36.40 & 37.90 & 38.90 \\
\hline 40 & 10 & 29.10 & 29.20 & 36.20 & 37.30 & 37.90 & 38.20 & 39.10 \\
\hline
\end{tabular}
polyphydramnios were excluded from the study. The cases where postnatal follow up was not found were also excluded from the study. Hence final study population constituted 787 healthy fetuses (Fig 1).

Ultrasonographic measurements were made by a real-time system with a $3.5-\mathrm{MHz}$ curvilinear transducer (ACUSON X150, Mountain View, CA 94043 USA). Gestational age (GA) was determined by two methods: first by knowing the first day of last menstrual period (GA by date) and second by sonographic measurement of four major parameters viz; Biparietal Diameter (BPD), Head circumference (HC), Abdominal Circumference $(\mathrm{AC})$ and Femur Length (FL) and obtaining the final average GA (GA by measurement). If the two methods match closely within \pm 14 days, then gestational age by date was considered final GA. But if there is discrepancy of > 14days; GA by measurement was considered final GA. In addition to these measurements, detailed evaluation of fetus was done from head to toe. Fetal pinna length was taken from the tip of helix to the end of lobe either in sagittal view or in coronal view (Fig 2 and 3). Two measurements were taken in each case and one of them was taken into consideration when both the measurements were close. But when there was some difference, third measurement was also taken and one of such as IUGR, structural anomalies, oligohydramnios, 
the two closely matched measurements was considered.

All the data were initially managed with MS excel programme and the statistical analyses were later performed by SPSS 11.5 software. The relationship between gestational age in weeks to pinna length in millimeters was analyzed by simple linear regression. For a given gestational age, predicted values were obtained for the 5th, 10th, 25th, 50th, 75th, 90th and 95th percentiles to develop a nomogram. Correlation of fetal ear length measurements with GA, HC and BPD were also obtained alongwith BPD/ Pinna Length ratio and $\mathrm{HC} /$ Pinna Length ratios.

Table 2. Summary of relationship of pinna length with GA, BPD and $\mathrm{HC}$

\begin{tabular}{|c|c|c|c|c|}
\hline$y$ axis & $\begin{array}{l}\mathrm{x} \text { axis } \\
\text { Gestational } \\
\text { age }\end{array}$ & $\begin{array}{l}\text { Regression } \\
\text { Formula } \\
y=1.044 x \\
-3.857\end{array}$ & $\begin{array}{l}\text { Correlation } \\
\text { Coefficient } \\
0.942\end{array}$ & $\begin{array}{l}\text { P value } \\
<0.001\end{array}$ \\
\hline $\begin{array}{l}\text { pinna } \\
\text { length }\end{array}$ & $\begin{array}{l}\text { BPD } \\
\mathrm{HC}\end{array}$ & $\begin{array}{l}y=0.392 x \\
-1.210 \\
y=0.109 x \\
-1.777\end{array}$ & $\begin{array}{l}0.934 \\
0.931\end{array}$ & $\begin{array}{l}0.004 \\
<0.001\end{array}$ \\
\hline
\end{tabular}

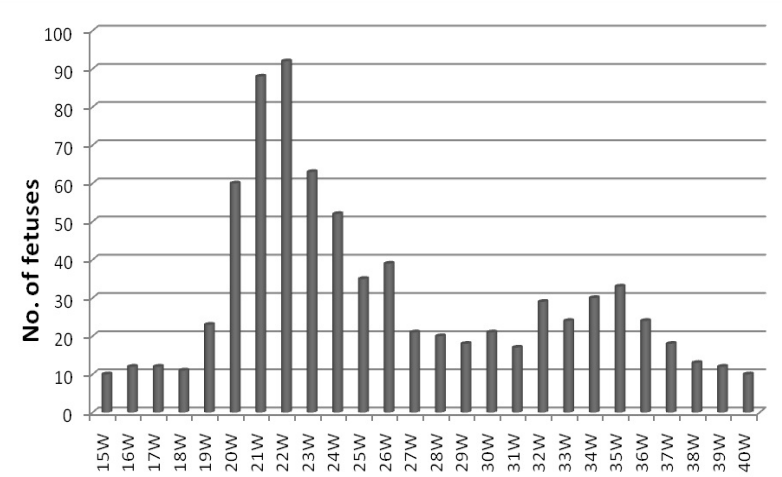

Figure 1. Frequency distribution of fetuses at various gestational age in weeks(W).

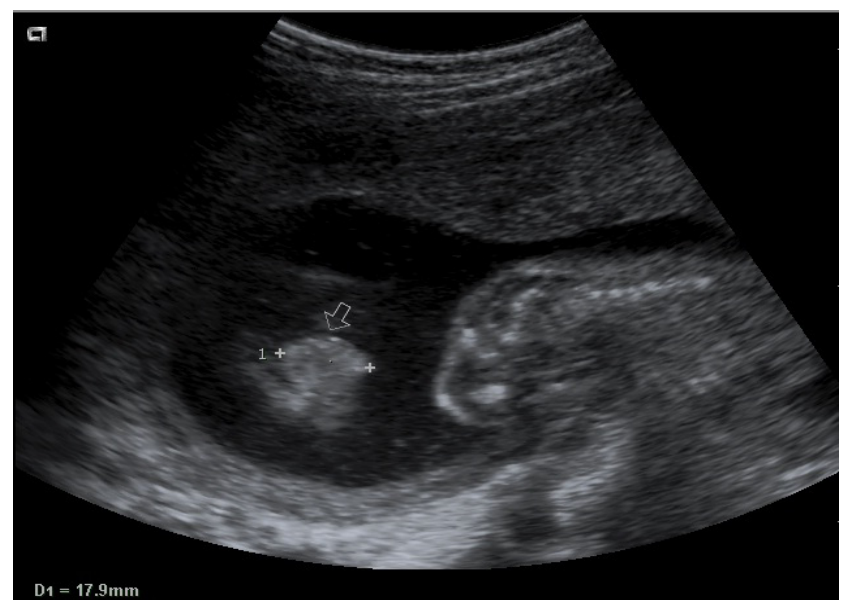

Figure 2. Fetal pinna length(open arrow) taken from the tip of helix to the end of lobe(cursors) in sagittal view at 20 weeks of gestation.

\section{RESULTS}

Linear relationships were found between fetal pinna length and gestational age (Fig 4). Pinna length in $\mathrm{mm}$ $=1.044 x$ Gestational age (weeks) -3.857. A nomogram was obtained with the predicted values at 5th, 10th, 25th, 50th, 75th, 90th and 95th percentiles (Table I). Linear relationship was also found between fetal pinna length and BPD (Fig 5) and Fetal Pinna length and $\mathrm{HC}$ (Fig 6). High correlation was found between pinna length and GA ( $r=0.942 ; p<0.001)$. Similar correlation was also found between pinna length and $\mathrm{HC}(r=0.931 ; p<0.001)$. Significant correlation was found between pinna length and BPD ( $r=0.934 ; p=0.004)$. Table II summarizes relationship and statistical correlation between pinna length and GA, BPD and HC.

$\mathrm{BPD} /$ Pinna length ratio and $\mathrm{HC} /$ Pinna length ratio were fairly constant throughout gestation (Fig 7 and 8). BPD/ Pinna Length ratio is approx. between 2.6-2.8 and $\mathrm{HC} /$ Pinna length ratio is approx. between 9.5-10.5.
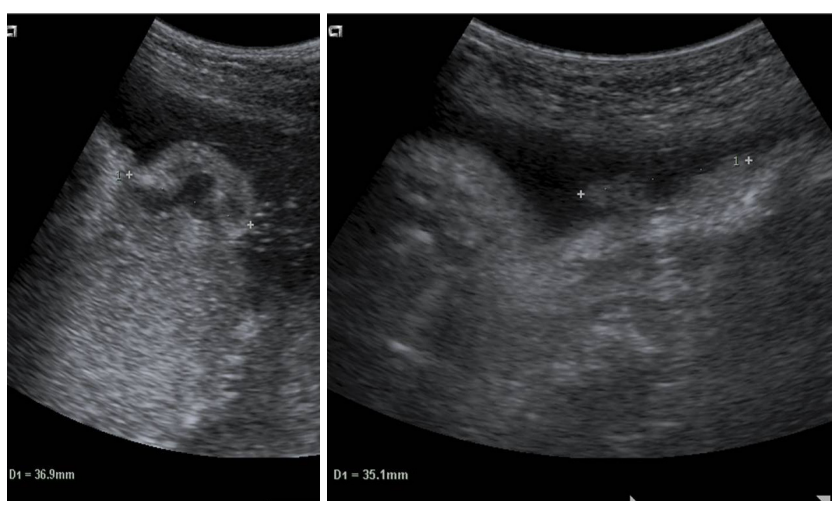

Figure 3. Fetal pinna (cursors) at 40 and 36 weeks of gestation in parasagittal and coronal views respectively.

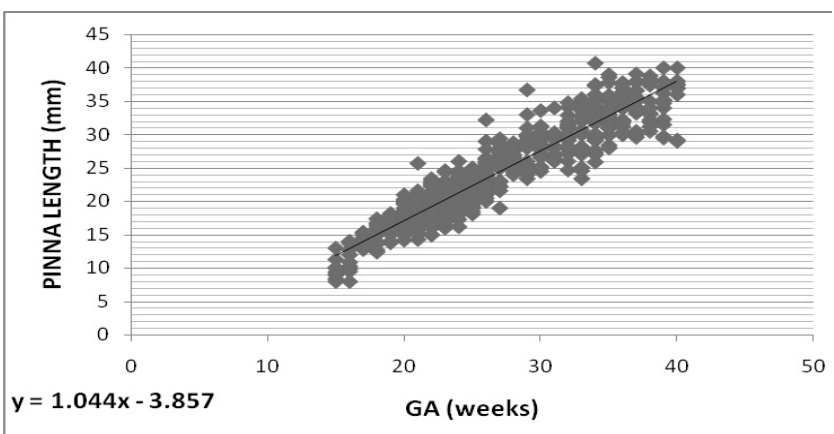

Figure 4. Relationship between pinna length(PL) with gestational age (GA).

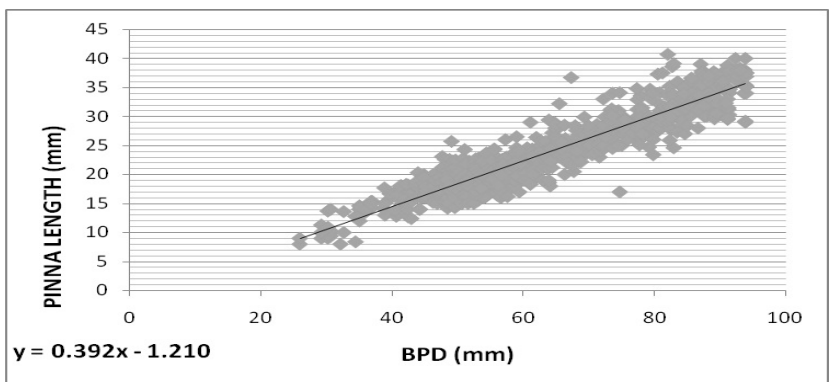

Figure 5. Relationship between pinna length (PL) with BPD. 


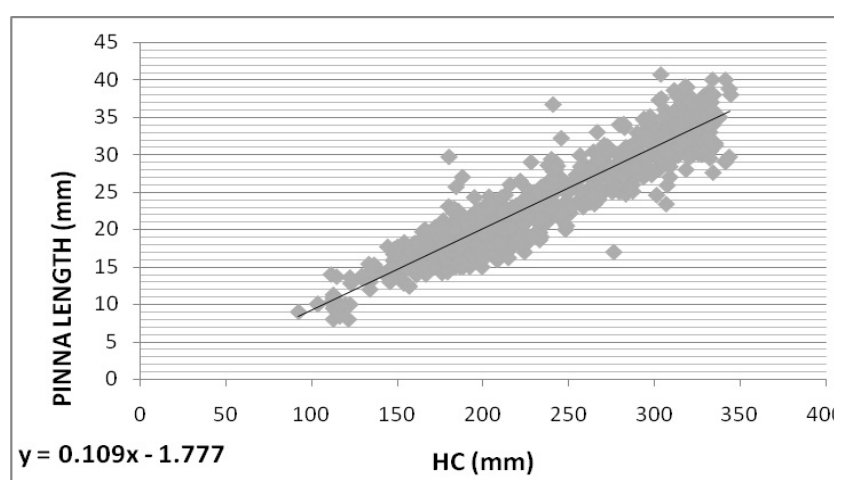

Figure 6. Relationship between pinna length (PL) with $\mathrm{HC}$.

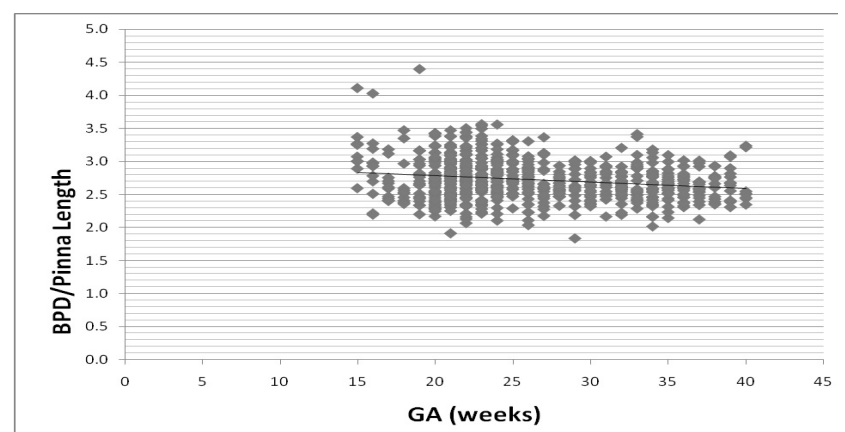

Figure 7. Scatterdiagram. BPD/pinaa length ratio vs GA(weeks).

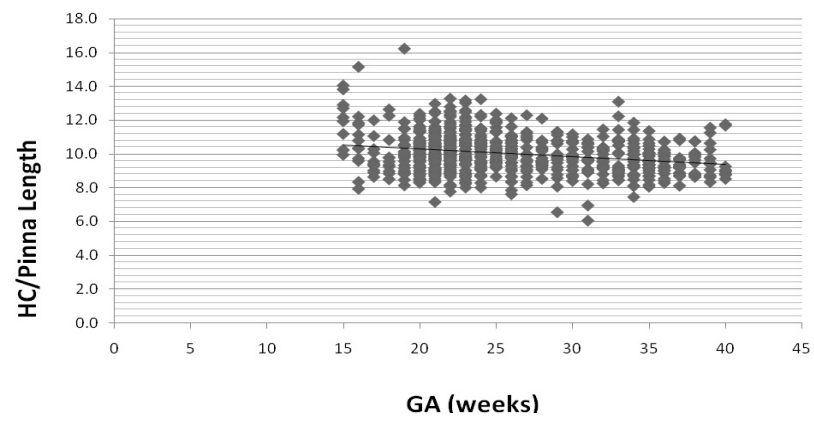

Figure 8. Scatterdiagram. HC/pinna length ratio vs GA(weeks).

\section{DISCUSSION}

At least three routine antenatal scans are performed regularly in all pregnant ladies visiting our hospital; one at first visit regardless of gestational age, second for anomaly scan between 18-22 weeks and third at the time of delivery. Additional scans are performed only if clinically indicated. One of the main objectives of these routine scans is to detect obvious fetal anomalies. Among these, the detection of fetal chromosomal anomalies and other aneuploid conditions is one of the challenging jobs. Various laboratory parameters are available for the detection of same viz; amniocentesis, chorionic villus sampling, single marker (maternal serum alpha fetoprotein) and multiple-marker biochemical screening tests. Apart from these, genetic sonograms are also being used to detect fetal aneuploidy. ${ }^{12,13}$ One of the sonographic parameters frequently used is fetal pinna length. ${ }^{7,8,14}$ In our experience, pinna length measurement is relatively simple and straightforward technique which can be obtained in nearly all fetal sonographic examinations.

Abnormally small pinna length is one of the most prominent and consistent features of trisomies and other aneuploidy. In their study, Sivan et al defined small ears as values less than the mean -2 SD. ${ }^{15}$ Only one study by Gill et al however does not agree that fetal ear measurements are diagnostically helpful due to wide range of normal variation seen at each gestational age. ${ }^{14}$ However many other studies are in favor of the fact that reduced fetal ear length is helpful in identifying fetal chromosomal anomalies. . $^{2,5,7}$ This prompted many investigators to use abnormal pinna length as potential additional parameters in the detection of these anomalies.

There are a number of studies providing ear length measurement for normal fetuses. These studies are mostly based on Western population. Our study is based entirely on Nepalese population. Our data suggest linear relationship between fetal pinna length and gestation age. This is in comparison with a study by Shimizu et al in which regression analysis was done in ultrasonologically obtained fetal ear length in 124 normal cases with $r=0.956 .{ }^{10}$ In their study, Chitkara et al developed a nomogram by linearly regressing ear length on gestational age and found a high correlation between them $(r=0.96 ; p=.0001) .{ }^{6}$ Birnholz et al in a study of 180 normal subjects found ear length increased from about $6 \mathrm{~mm}$ at 15 weeks to $33 \mathrm{~mm}$ at term and this was well fit by linear regression ( $r 2-0.96) .{ }^{9}$ Lettieri et al also found linear relationship between ear length and gestational age across second trimester. ${ }^{2}$ Though all of these studies including our study were cross sectional in nature, they also perhaps indicate linear pattern for length increment for individual cases in the second and third trimester cases. We have formulated a nomogram that is similar to the nomograms of previous studies. ${ }^{6,16}$ This shows that fetal pinna growth and size in our population is similar to that of Western population.

Unlike previous studies we did not include karyotyping as one of the criterion to define normal fetus due to lack of availability of such test in our setting. ${ }^{6,10}$ Normal fetus is defined on the basis of normal ultrasonographic examination and normal outcome at birth.

Other observations in our study include linear relationship between BPD and pinna length, $\mathrm{HC}$ and pinna length. This is in accordance with previous studies by Shimizu et al and Chitkara et al. ${ }^{6,10}$ We also observed BPD/pinna length ratio and $\mathrm{HC} /$ pinna length ratio which remain relatively constant throughout gestation. This means there is uniform rate of growth of these parameters. Any significant deviations in these ratios could also potentially be used as an additional parameter to detect chromosomal abnormalities. Normal BPD/ pinna length ratio is approx. between 2.6-2.8 in our study. In their study Chitkara et al noted an increased BPD/ ear length ratio of $\geq 4.0$ in fetuses with abnormal karyotype. $^{8}$

Abnormally short pinna is not only seen in chromosomal anomalies but also in other structural abnormalities. ${ }^{17}$ Hence antenatal evaluation of fetal pinna may be a useful adjunct to detect various other fetal congenital anomalies apart from chromosomal abnormalities and other aneuploidy. We do agree with Birnholz et al and suggest 
pinna length be determined ultrasonologically whenever risk or suspicion of a chromosomal disorder is present or when a fetal anomaly is detected. ${ }^{9}$

We have developed a nomogram to detect deviations from normal pinna length. This will help radiologists/ sonologists/ obstetricians to detect abnormal pinna and suspect underlying fetal abnormalities. We have also formulated BPD/Pinna Length and $\mathrm{HC}$ / Pinna Length ratios which can also be additional markers to detect abnormality.

\section{CONCLUSION}

The results of this study provide a nomogram for fetal pinna length at various gestational ages. The study also provides relationship and good correlation between pinna length and GA, BPD and HC. Large scale study is recommended in both antenatally and postnatally detected fetal anomalies in our part of world regarding the utility of these observations possibly in adjunct with karyotyping.

\section{ACKNOWLEDGEMENT}

Our sincere thanks to Dr. Rajendra Koju, Sujan B Marahatta, Dr. Pankaj Pant, Prerana Shrestha, Anisha Shrestha, Ruth and Roshan Mahato.

\section{REFERENCES}

1. Aase JM, Wilson AC, Smith DW. Small ear in Down's syndrome: a helpful diagnostic aid. J Pediatr 1973;82:845-7.

2. Lettieri L, Rodis JF, Vintzileos AM, Feeney L, Ciarleglio L, Craffey A. Ear length in second-trimester aneuploid fetuses. Obstet Gynecol $1993 ; 81: 57-60$

3. Nyberg DA, Kramer D, Resta RG, Kapur R, Mahony BS, Luthy DA, Hickok D. Prenatal sonographic findings of trisomy 18: review of 47 cases. J Ultrasound Med 1993;12:103-13.

4. Awward JT, Azar GB, Karam KS, Nicolaides KH. Ear length: A potential sonographic marker for Down syndrome. Int J Gynecol Obstet 1994;44:233-8.

5. Shimizu T, Salvador L, Hughes-Benzie R, Dawson L, Nimrod C, Allanson J. The role of reduced ear size in the prenatal detection of chromosomal abnormalities. Prenat Diagn 1997;17:545-9.

6. Chitkara U, Lee L, El-Sayed YY, Holbrook RH, Bloch DA, Oehlert JW, Druzin ML. Ultrasonographic ear length measurement in normal second- and third-trimester fetuses. Am J Obstet Gynecol 2000; 183(1):230-4.

7. Ruangchainikom W, Sarapak S. Utrasonographic Fetal Ear Measurement in Predicting Fetal Chromosome Abnormality. Thai J Obstet Gynecol 2001;13(3):147-50.

8. Chikara U, Lee L, Oehlert JW, Bloch DA, Holbrook RH, El-Sayed YY, Druzin ML. Fetal ear length measurement: a useful predictor of aneuploidy? Ultrasound Obstet Gynecol 2002;19:131-5.

9. Birnholz JC, Farrell EE. Fetal ear length. Pediatrics 1988;81:555-8.
10. Shimizu T, Salvador L, Allanson J, Hughes-Benzie R, Nimrod C. Ultrasonographic measurement of fetal ear. Obstet Gynecol 1992;80:381-4.

11. Shih J-C, Shyu M-K, Lee C-N, Wu C-H, Lin G-J, Hsieh F-J. Antenatal depiction of the fetal ear with three-dimensional ultrasonography. Obstet Gynecol 1998;91:500-5.

12. Benacerraf BR, Nadel A, Bromley B. Identification of second-trimester fetuses with autosomal trisomy by use of a sonographic scoring index. Radiology 1994;193:135-40.

13. Vintzileos AM, Campbell WA, Rodis JF, Guzman ER, Smulian JC, Knuppel RA. The use of second-trimester genetic sonogram in guiding clinical management of patients at increased risk for fetal trisomy 21. Obstet Gynecol 1996;87:948-52.

14. Gill P, Vanhook J, Fitzsimmons J, Pascoe-Mason J, Fantel A. Fetal ear measurements in the prenatal detection of trisomy 21.Prenat Diagn 1994;14:739-43.

15. Sivan Y, Merlob P, Reisner SH. Assessment of ear length and low set ears in newborn infants. J Med Genet 1983;20:213-5.

16. Yeo L, Guzman ER, Ananth CV, Walters C, Salvatore DD, Vintzileos AM. Prenatal Detection of Fetal Aneuploidy by Sonographic Ear Length. J Ultrasound Med 2003;22:565-76.

17. Hutchinson JC Jr, Caldarelli DD, Gould HJ. Classification and multidisciplinary management of microtia.Otolaryngol Clin North Am 1981;14:855-87. 